\title{
Determinants of hypertension among adults living in Bole Sub-city, Addis Ababa
}

\author{
Selam Ayele Kassie ${ }^{1}$, Kidanemariam G/Michael Beyene ${ }^{2}$, Mesafint Abeje Tiruneh ${ }^{3}$ \\ ${ }^{1}$ Tirunesh Beijing General Hospital, Addis Ababa, Ethiopia \\ ${ }^{2}$ Ethiopian Food, Medicine and Healthcare Administration and Control Authority, Addis Ababa, Ethiopia \\ ${ }^{3}$ Bethzatha General Hospital, Addis Ababa, Ethiopia
}

\section{Article Info \\ Article history: \\ Keywords: \\ Addis Ababa \\ Adult \\ Case-Control \\ Determinants \\ Ethiopia \\ Hypertension}

Received Mar 5, 2020

Revised Apr 17, 2020

Accepted May 1, 2020

\begin{abstract}
Complications of hypertension account for 9.4 million deaths world wide every year. Evidences indicated that hypertension and elevated blood pressure are increasing partly due to increase in determinants. In Addis Ababa, there is limited information on determinants of hypertension among adults. Hence, this study aimed to assess determinants of hypertension among adults living in Bole Sub-city, Addis Ababa. Community based unmatched case-control study was conducted. Simple random sampling technique was used to select 122 cases and 244 controls. Data were collected using interviewer administered structured questionnaire and measurement of blood pressure, weight and height. Binary logistic regression model was used for data analysis. A total of 348 adults were included in the study with $95 \%$ response rate. The study showed that age (AOR=7.68, 95\% CI: 2.31-25.48), average family monthly in come (AOR=6.39, CI: $1.60-25.55)$, family history of hypertension (AOR=4.50, CI: 1.14-17.62), body mass index $(\mathrm{AOR}=3.76$, CI: 1.49-9.48), physical activity (AOR=3.66, CI: 1.21-11.07), tobacco use (AOR=8.99,CI:2.02-39.86), salt consumption (AOR=5.22, CI: 1.47-18.48), stress $(\mathrm{AOR}=5.18, \mathrm{CI}: 2.42-11.09)$, knowledge $(\mathrm{AOR}=8.82$, CI: 3.14-24.72) and diabetic mellitus (AOR=8.42, CI: 1.44-48.97) were significantly associated with hypertension. Cases had higher exposure to risk factors of hypertension than controls. Age, average family monthly income, physical activity, saltcon sumption, diabetic mellitus, stress, tobacco use, body mass index, family history of hypertension and knowledge were associated with hypertension. There is a need to health education to prevent tobacco use, regular exercise, reduce salt consumption and other life style modifications to reduce hypertension.
\end{abstract}

This is an open access article under the CC BY-SA license.

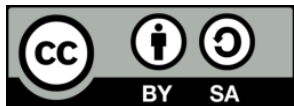

\section{Corresponding Author:}

Selam Ayele Kassie,

Tirunesh Beijing General Hospital,

Addis Ababa, Ethiopia.

Email: selamayele13@gmail.com

\section{INTRODUCTION}

Non-communicable diseases were attributable to around three-quarters of the total global mortalities in 2017. Cardiovascular disease was the dominant cause of non-communicable disease related morbidities and mortalities [1]. Uncontrolled hypertension is the leading risk factor for cardiovascular disease [2]. The burden of hypertension in developing countries is increasing [3].

Hypertension, known as high or raised blood pressure, is a global public health concerns. It contributes to the burden of heart disease, stroke and kidney failure, and premature mortality and disability [4]. Globally, the magnitude of hypertension was 1.39 billion population [5]. Most people with 
hypertension experiences two-fold higher risk of developing coronary artery disease, four times higher risk of congestive heart failure and seven times higher risk of cerebrovascular disease [6]. Cardiovascular disease is the leading global cause of death, accounting for more than 17.3 million deaths per year, a number that is expected to grow to greater than 23.6 million by 2030. Of these, complications of hypertension accounts for 9.4 million deaths worldwide per year. In 2013, cardiovascular deaths were $31 \%$ of all global deaths. The greatest burden of cardiovascular disease was in low and middle-income countries (LMICs), with approximately $80 \%$ of cardiovascular deaths [7].

There is a disparity in prevalence of hypertension between high-income and, low and middle-income countries. From 2000 to 2010, hypertension prevalence decreased by $2.6 \%$ in high-income countries, but in low and middle-income countries it increased by 7.7\%. Almost three times more people with hypertension live in developing countries (1.04 billion people) than developed countries (694 million people) [5]. The World Health Organization (WHO) estimated that hypertension prevalence is highest in African region with about $46 \%$ of adults aged 25 years and older was hypertensive. In Africa, people with hypertension increased from 54.6 million in 1990 to 92.3 million in 2000, 130.2 million in 2010 and could increase to 216.8 million by 2030 [8]. A study conducted in Nigeria indicated hypertension prevalence among Nigerian population was predicted to be $44.9 \%$ [9].

Evidences indicated that hypertension and elevated blood pressure are increasing partly due to increase in smoking, obesity, harmful use of alcohol, lack of exercise and other risk factors [10]. Hypertension mainly associated with lifestyle and environmental factors rather than genetics. It has stronger causal link with tobacco use, excessive use of alcohol, physical inactivity, unhealthy diet and obesity. The risk factors that lead to hypertension can be reversible or irreversible [11]. Different determinants have been known as hypertension risk factors. Socio-demographic characteristics, including sex, age, diabetes mellitus, parental hypertension history, sleep duration, body mass index, smoking and alcohol consumption were statistically associated with hypertension [12].

A study done in Ethiopia revealed that hypertension prevalence among Ethiopian population was about $19.6 \%$. The prevalence of hypertension was higher in the urban population [13]. A study conducted in Addis Ababa indicated that hypertension prevalence was $25 \%$ which is significantly higher in men than women [14]. A similar studies showed that prevalence of hypertension was $28.3 \%$ in Amhara region (Gondar), $16.9 \%$ in Oromia region (Bedele), $22.4 \%$ in Southern region (Durame), 18.1\% in Tigray region (Humera) and $30.2 \%$ in Addis Ababa [13]. Another survey conducted in Addis Ababa also showed that 25\% were found to have hypertensive and $35.4 \%$ of hypertensive found in Bole sub city [14].

Awareness about prevention, treatment and control of hypertension is very low and there is limited information on determinants of hypertension. The previous studies conducted in Addis Ababa mainly focused on prevalence of hypertension showed various risk factors that have been linked with hypertension but there are studies that contradict about determinant factors which may be because of the study design weakness. The findings of this study will provide information for policymakers and concerned stakeholders to devise effective strategies and appropriate interventions to reduce the determinants of hypertension. Hence, this study aimed to assess determinants of hypertension among adults living in Bole Sub-city in Addis Ababa, Ethiopia.

\section{RESEARCH METHOD}

\subsection{Study design and setting}

Community-based unmatched case-control study was employed to identify determinants of hypertension among adults living in Bole sub-city, Addis Ababa, Ethiopia. Data were collected from August 18 to September 28, 2018. Addis Ababa is the diplomatic capital of the African Union and capital city of Ethiopia. It has ten sub-cities and 116 districts. The city has an estimated population of 3,384,569. Bole Sub-city is one of the Sub-cities of Addis Ababa. Bole Sub-city has 14 districts with estimated population of 308,995 (145,225 males and 163,770 females). In addition, there are 79,020 households in Bole Sub-city [15].

\subsection{Study population}

The study population was adults living in Bole sub-city in Addis Ababa. Cases were in age of $>25$ years old with systolic blood pressure $\geq 140 \mathrm{mmHg}$ and/or diastolic blood pressure $\geq 90 \mathrm{mmHg}$ or those who were taking antihypertensive drugs; and controls were in the age of $>25$ years old with systolic blood pressure $<140 \mathrm{mmHg}$ and/or diastolic blood pressure $<90 \mathrm{mmHg}$ and who did not report a history of hypertension were included in the study. Those who were critically sick during the data collection period were excluded from the study. 


\subsection{Sample size determination}

The sample size was calculated using double population proportion formula for predictor variables by using EPI-info version 7.2.1.0 and considering; 95\% confidence level, 80\% power, case to controls ratio of 1:2 and proportions of hypertension taken from a study conducted in Bahir Dar [16]. Hence, the required sample size for the study was 366 of which 122 cases and 244 controls.

\subsection{Sampling procedure}

To select the study participants, simple random sampling technique was used. Lists of districts were obtained from Sub-city. The districts were listed, and lottery method was employed to randomly draw the required number of districts. Hence, four districts (30\% of the total districts) were selected from the 14 districts of Bole Sub-city. To select the number of study participants, equal allocation of study participants was done. Ninety-two participants were selected from each selected districts. The study participants were selected from each household until the required sample size obtained.

\subsection{Data collection procedures and quality assurance}

Interviewer administered structured questionnaire adapted from WHO [17] and weight, height and blood pressure measurements were used to collect the data. The questionnaire was first developed in English and then translated into local language (Amharic) for appropriateness and easiness in approaching the study participants and back translated to English language to check its consistency of meaning. Before the commencement of the actual data collection, the questionnaire was pretested on 5\% randomly selected residents who were later excluded from the study. The pre-testing did not lead to major changes in the questionnaire, except correction of few typographical mistakes. The questionnaire was consisted of questions related to socio-demographic characteristics, life style, stress, knowledge, and renal disease and diabetic mellitus status.

The data collection methods were face-to-face interviews and physical measurements of height, weight and blood pressure. Height and weight were measured with a standard and calibrated instrument. Blood pressure was measured using a standard measuring device with the participant sitting after resting for at least five minutes and two blood pressure readings were taken on all participants and an average of the readings was used to declare the presence or absence of hypertension. Eight nurses with substantial experience in data collection were recruited and trained for one day on study objective, data collection procedures and instruments, participants approach, confidentiality and right of the study participants before the data collection period. Consistency and completeness of the collected data were checked before any effort to enter code and analyze it. Each day, $10 \%$ of the completed questionnaires were reviewed and checked for completeness and relevance.

\subsection{Data management and analysis}

Epi-Info version 7.2.1.0 statistical software was used for data coding, entry and cleaning. The cleaned data were imported to SPSS version 23.0 for analysis. Descriptive analysis was performed as appropriate and results were presented in tables. At $25 \%$ level of significance, bivariate analyses were done to identify potentially significant independent predictors with the outcome variable. The independent variables that were associated with dependent variable in bivariate analysis were included in multiple logistic regression analysis. The association between dependent variable and independent variables were analysed using Binary Logistic Regression Model. Hosmer and Lemeshow Goodness-of-fit test was used to check adequacy of the final model and fitted to the data well ( $p$-value $=0.375$ ). For Binary Logistic Regression Model; AOR at $95 \% \mathrm{CI}$ were computed and variables with p-value less than 0.05 were considered as statistically significant to dependent variable.

\section{RESULTS AND DISCUSSIONS}

\subsection{Results}

\subsubsection{Socio-demographic factors of the study participants}

From the 366 participants, 348 adults were participated in the study which makes the response rate of $95.0 \%$. Fifty-nine cases and 131 controls (54.6\%) were males and 32 cases and 112 controls $(41.4 \%)$ were 25-35 years old. About 47 cases and 118 controls (47.4\%) were single. Forty-two cases and 67 controls $(31.3 \%)$ were self-employed, and 25 cases and 79 controls $(29.9 \%)$ had degree and above education level. About 50 cases and 126 controls $(50.6 \%$ ) had less than 5,000.00 Ethiopian Birr average family monthly income. Furthermore, 99 cases and 219 controls $(91.4 \%)$ had no family history of hypertension and 64 cases and 155 controls $(62.9 \%)$ had normal body mass index that can be seen in Table 1. 
Table 1. Socio-demographic factors of adult population in Bole Sub-city, Addis Ababa

\begin{tabular}{|c|c|c|c|c|}
\hline Variables & Category & Cases, n (\%) & Controls, n (\%) & Total, n (\%) \\
\hline \multirow{2}{*}{ Sex } & Male & $59(31.1)$ & $131(68.9)$ & $190(54.6)$ \\
\hline & Female & $57(36.1)$ & $101(63.9)$ & $158(45.4)$ \\
\hline & $25-35$ & $32(22.2)$ & $112(77.8)$ & $144(41.4)$ \\
\hline \multirow[t]{3}{*}{ Age in years } & $36-45$ & $38(34.2)$ & $73(65.8)$ & $111(31.9)$ \\
\hline & $>45$ & $46(49.5)$ & $47(50.5)$ & $93(26.7)$ \\
\hline & Single & $47(28.5)$ & $118(71.5)$ & $165(47.4)$ \\
\hline \multirow{4}{*}{ Marital status } & Married & $56(36.1)$ & $99(63.9)$ & $155(44.5)$ \\
\hline & Divorced & $9(45.0)$ & $11(55.0)$ & $20(5.7)$ \\
\hline & Widowed & $4(50.0)$ & $4(50.0)$ & $8(2.3)$ \\
\hline & House wife & $11(61.1)$ & $7(38.9)$ & $18(5.2)$ \\
\hline \multirow{7}{*}{ Occupation } & Government employee & $4(10.0)$ & $36(90.0)$ & $40(11.5)$ \\
\hline & Private employee & $28(40.6)$ & $41(59.4)$ & $69(19.8)$ \\
\hline & Daily laborer & $1(9.1)$ & $10(90.9)$ & $11(3.2)$ \\
\hline & Self-employed & $42(38.5)$ & $67(61.5)$ & $109(31.3)$ \\
\hline & NGO & $2(7.4)$ & $25(92.6)$ & $27(7.8)$ \\
\hline & Merchant & $18(35.3)$ & $33(64.7))$ & $51(14.7)$ \\
\hline & Others (retire, student, unemployed) & $10(43.5)$ & $13(56.5)$ & $23(6.6)$ \\
\hline \multirow{6}{*}{ Educational status } & Illiterate & $12(80.0)$ & $3(20.0)$ & $15(4.3)$ \\
\hline & Read and write & $9(50.0)$ & $9(50.0)$ & $18(5.2)$ \\
\hline & Primary school & $24(41.4)$ & $34(58.6))$ & $58(16.7)$ \\
\hline & Secondary school & $30(36.6)$ & $52(63.4)$ & $82(23.5)$ \\
\hline & Diploma or TVET & $16(22.5)$ & $55(77.5)$ & $71(20.4)$ \\
\hline & Degree and above & $25(24.0)$ & $79(76.0)$ & $104(29.9)$ \\
\hline \multirow{3}{*}{$\begin{array}{l}\text { Family average monthly income } \\
\text { in Ethiopian Birr }\end{array}$} & $<5000.00$ & $50(28.4)$ & $126(71.6)$ & $176(50.6)$ \\
\hline & $5000.00-10,000.00$ & $39(33.1)$ & $79(66.9)$ & $118(33.9)$ \\
\hline & $>10,000.00$ & $27(50.0)$ & $27(50.0)$ & $54(15.5)$ \\
\hline \multirow{2}{*}{ Family history of hypertension } & Yes & $17(56.7)$ & $13(43.3)$ & $30(8.6)$ \\
\hline & No & $99(31.1)$ & $219(68.9)$ & $318(91.4)$ \\
\hline \multirow{3}{*}{ Body mass index (BMI) } & Under weight & $3(10.0)$ & $27(90.0)$ & $30(8.6)$ \\
\hline & Normal weight & $64(29.2)$ & $155(70.8)$ & $219(62.9)$ \\
\hline & Over weight & $49(49.5)$ & $50(50.5)$ & $99(28.4)$ \\
\hline
\end{tabular}

\subsubsection{Life style characteristics}

The study showed that 99 cases and 222 controls $(92.2 \%)$ were non tobacco users and 74 cases and 193 controls $(76.7 \%)$ were non-alcohol consumers. About 48 cases and 111 controls (45.7\%) were physically active. In addition, 89 cases and 208 controls $(85.3 \%$ ) had optimal salt consumption that can be seen in Table 2 .

Table 2. Life style characteristics of adult population in Bole Sub-city, Addis Ababa

\begin{tabular}{ccccc}
\hline Variables & Category & Cases, $\mathrm{n}(\%)$ & Controls, $\mathrm{n}(\%)$ & Total, $\mathrm{n}(\%)$ \\
\hline \multirow{2}{*}{ Tobacco use } & Non user & $99(30.8)$ & $222(69.2)$ & $321(92.2)$ \\
& Current user & $11(64.7)$ & $6(35.3)$ & $17(4.9)$ \\
& Past user & $6(60.0)$ & $4(40.0)$ & $10(2.9)$ \\
& Non consumer & $74(27.7)$ & $193(72.3)$ & $267(76.7)$ \\
Alcohol consumption & Current consumer & $30(51.7)$ & $28(48.3)$ & $58(16.7)$ \\
& Past consumer & $12(52.2)$ & $11(47.8)$ & $23(6.6)$ \\
& Active & $37(26.8)$ & $101(73.2)$ & $138(39.7)$ \\
Physical activity & Optimal & $48(30.2)$ & $111(69.8)$ & $159(45.7)$ \\
& Inactive & $31(60.8)$ & $20(39.2)$ & $51(14.7)$ \\
& Low & $3(15.0)$ & $17(85.0)$ & $20(5.7)$ \\
Salt consumption & Optimal & $89(30.0)$ & $208(70.0)$ & $297(85.3)$ \\
& High & $24(77.4)$ & $7(22.6)$ & $31(8.9)$ \\
\hline
\end{tabular}

\subsubsection{Stress and morbidity characteristics}

Among the total study participants, 52 cases and 45 controls $(28.9 \%)$ had stress, nine cases and three controls (3.4\%) had diabetes mellitus and 10 cases and eight controls (5.2\%) had renal disease that can be seen in Table 3 .

Table 3. Stress and morbidity characteristics among adult population in Bole Sub-city, Addis Ababa

\begin{tabular}{ccccc}
\hline Variables & Category & Cases, $\mathrm{n}(\%)$ & Controls, $\mathrm{n}(\%)$ & Total, $\mathrm{n}(\%)$ \\
\hline \multirow{2}{*}{ Stress } & Yes & $52(53.6)$ & $45(46.4)$ & $97(28.9)$ \\
& No & $64(25.5)$ & $187(74.5)$ & $251(72.1)$ \\
Diabetes mellitus & Yes & $9(75.0)$ & $3(25.0)$ & $12(3.4)$ \\
& No & $107(31.8)$ & $229(68.2)$ & $336(96.6)$ \\
\multirow{2}{*}{ Renal disease } & Yes & $10(55.6)$ & $8(44.4)$ & $18(5.2)$ \\
& No & $106(32.1)$ & $224(67.9)$ & $330(94.8)$ \\
\hline
\end{tabular}

Int. J. Public Health Sci, Vol. 9, No. 2, June 2020: 121 - 128 


\subsubsection{Knowledge level}

Out of the total study participants, 74 cases and 122 controls (56.3\%) had poor knowledge and 39 cases and 94 controls (38.2\%) had medium knowledge about hypertension that can be seen in Table 4.

Table 4. Knowledge level of study participants, Addis Ababa

\begin{tabular}{cccc}
\hline Knowledge level & Cases, $\mathrm{n}(\%)$ & Controls, $\mathrm{n}(\%)$ & Total, $\mathrm{n}(\%)$ \\
\hline Good knowledge & $3(15.8)$ & $16(84.2)$ & $19(5.5)$ \\
Medium Knowledge & $39(29.3)$ & $94(70.4)$ & $133(38.2)$ \\
Poor knowledge & $74(37.8)$ & $122(62.2)$ & $196(56.3)$ \\
\hline
\end{tabular}

\subsubsection{Determinants of hypertension}

At 25\% level of significance bivariate binary logistic regression analysis marital status, occupation, family average monthly income, age, education level, family history of hypertension, tobacco use, alcohol consumption, stress, knowledge, diabetic mellitus status, renal disease, physical activity, salt consumption and body mass index were significantly associated with hypertension. However, in multivariable binary logistic regression analysis; age, average family monthly income, family history of hypertension, tobacco use, physical activity, salt consumption, stress, knowledge, diabetic mellitus and body mass index were significantly associated with hypertension.

The odds of developing hypertension among respondents of age 36-45 years and $>45$ years were 6.07 and 7.68 times the odds of those aged 25-35 years respectively (AOR=6.07, 95\% CI: 2.34-15.79 and $\mathrm{AOR}=7.68,95 \% \mathrm{CI}: 2.31-25.48$ ). The odds of developing hypertension among respondents with average family monthly income of $>10,000.00$ Ethiopian Birr were 6.39 times the odds of those with average family monthly income of less than 5000.00 Ethiopian Birr (AOR=6.39, 95\% CI: 1.60-25.55). The odds of developing hypertension among respondents who had family history of hypertension were 4.50 times the odds of those who had no family history of hypertension (AOR=4.50, 95\% CI: 1.14-17.62). The odds of developing hypertension among respondents who had over weight were 3.76 times the odds of those who had normal weight $(\mathrm{AOR}=3.76,95 \% \mathrm{CI}$ : 1.49-9.48). The odds of developing hypertension among respondents who use tobacco currently were 8.99 times the odds of those who never use tobacco (AOR=8.99, 95\% CI: 2.02-39.86). The odds of developing hypertension among respondents who are physically inactive were 3.66 times the odds of those who are physically active (AOR=3.66, 95\% CI: 1.21-11.07). The odds of developing hypertension among respondents who had high salt consumption were 5.22 times the odds of those who had optimal salt consumption ( $\mathrm{AOR}=5.22,95 \% \mathrm{CI}$ : 1.47-18.48). The odds of developing hypertension among respondents who had stress were 5.18 times the odds of those who had no stress (AOR=5.18, 95\% CI: 2.42-11.09). The odds of developing hypertension among respondents who had poor knowledge were 8.82 times the odds of those who had medium knowledge about hypertension ( $\mathrm{AOR}=8.82$, 95\% CI: 3.14-24.72). In addition, the odds of developing hypertension among respondents who had diabetes mellitus were 8.42 times the odds of those who had no diabetes mellitus (AOR=8.42, 95\% CI: 1.44-48.97) that can be seen in Table 5 .

Table 5. Bivariate and multivariable binary logistic regression analysis for factors associated with hypertension among adults living in Bole Sub-city, Addis Ababa

\begin{tabular}{|c|c|c|c|c|c|c|}
\hline \multirow{2}{*}{ Variable } & \multirow{2}{*}{ Category } & \multicolumn{2}{|c|}{ Hypertension } & \multirow{2}{*}{ COR $(95 \% \mathrm{CI})$} & \multirow{2}{*}{$\operatorname{AOR}(95 \% \mathrm{CI})$} & \multirow{2}{*}{ P-value } \\
\hline & & Yes & No & & & \\
\hline \multirow{3}{*}{ Age in years } & $25-35$ & 32 & 112 & 1 & 1 & \\
\hline & $36-45$ & 38 & 73 & $1.82(1.05-3.17)$ & $6.08(2.34-15.79)$ & $0.000 *$ \\
\hline & $>45$ & 46 & 47 & $3.43(1.95-6.03)$ & $7.68(2.32-25.48)$ & $0.001 *$ \\
\hline \multirow{6}{*}{ Educational level } & Illiterate & 12 & 3 & $0.08(0.02-0.30)$ & $4.91(0.57-42.30)$ & 0.147 \\
\hline & Read and write & 9 & 9 & $0.32(0.11-0.88)$ & $1.60(0.37-6.93)$ & 0.530 \\
\hline & Primary school & 24 & 34 & $0.45(0.23-0.89)$ & $2.12(0.62-7.29)$ & 0.232 \\
\hline & Secondary school & 30 & 52 & $0.55(0.29-1.04)$ & $0.99(0.35-2.82)$ & 0.988 \\
\hline & Diploma or TVET & 16 & 55 & $1.09(0.53-2.23)$ & $0.48(0.17-1.37)$ & 0.169 \\
\hline & Degree and above & 25 & 79 & 1 & 1 & \\
\hline \multirow{4}{*}{ Marital status } & Single & 47 & 118 & 1 & 1 & \\
\hline & Married & 56 & 99 & $1.42(0.89-2.27)$ & $0.67(0.30-1.47)$ & 0.314 \\
\hline & Divorced & 9 & 11 & $2.05(0.80-5.28)$ & $0.40(0.09-1.87)$ & 0.245 \\
\hline & Widowed & 4 & 4 & $2.51(0.60-10.46)$ & $0.40(0.03-5.18)$ & 0.480 \\
\hline \multirow{8}{*}{ Occupation } & House wife & 11 & 7 & $2.51(0.90-6.97)$ & $2.82(0.56-14.15)$ & 0.207 \\
\hline & Government employee & 4 & 36 & $0.18(0.06-0.53)$ & $0.44(0.10-1.98)$ & 0.283 \\
\hline & Private employee & 28 & 41 & $1.09(0.59-2.02)$ & $3.28(1.19-9.01)$ & 0.021 \\
\hline & Daily laborer & 1 & 10 & $0.16(0.02-1.29)$ & $0.71(0.05-9.43)$ & 0.793 \\
\hline & Self-employee & 42 & 67 & 1 & 1 & \\
\hline & NGO employee & 2 & 25 & $0.13(0.03-0.57)$ & $0.05(0.01-0.33)$ & 0.002 \\
\hline & Merchant & 18 & 33 & $0.87(0.44-1.74)$ & $0.94(0.31-2.82)$ & 0.909 \\
\hline & Other & 10 & 13 & $1.23(0.49-3.05)$ & $1.46(0.36-6.00)$ & 0.598 \\
\hline
\end{tabular}

Determinants of hypertension among adults living in Bole Sub-city, Addis Ababa ...(Selam Ayele Kassie) 


\begin{tabular}{|c|c|c|c|c|c|c|}
\hline \multirow{2}{*}{ Variable } & \multirow{2}{*}{ Category } & \multicolumn{2}{|c|}{ Hypertension } & \multirow{2}{*}{$\operatorname{COR}(95 \% \mathrm{CI})$} & \multirow{2}{*}{$\operatorname{AOR}(95 \% \mathrm{CI})$} & \multirow{2}{*}{$\mathrm{P}$-value } \\
\hline & & Yes & No & & & \\
\hline \multirow{3}{*}{$\begin{array}{l}\text { Average family } \\
\text { monthly income }\end{array}$} & $<5000$ birr & 50 & 126 & 1 & 1 & \\
\hline & $5000-10,000$ birr & 39 & 79 & $1.24(0.75-2.06)$ & $1.75(0.79-3.87)$ & 0.170 \\
\hline & $>10,000$ birr & 27 & 27 & $2.52(1.35-4.71)$ & $6.40(1.60-25.55)$ & $0.009 *$ \\
\hline \multirow{3}{*}{$\begin{array}{l}\text { Family history of } \\
\text { hypertension }\end{array}$} & Yes & 17 & 13 & $2.89(1.35-6.19)$ & $4.50(1.15-17.63)$ & $0.031 *$ \\
\hline & No & 99 & 219 & 1 & 1 & \\
\hline & Under weight & 3 & 27 & $0.27(0.08-0.92)$ & $0.45(0.09-2.32)$ & 0.341 \\
\hline \multirow[t]{3}{*}{ Body mass index } & Normal weight & 64 & 155 & 1 & 1 & \\
\hline & Over weight & 49 & 50 & $2.37(1.45-3.87)$ & $3.77(1.50-9.49)$ & $0.005^{*}$ \\
\hline & Non user & 99 & 222 & 1 & 1 & \\
\hline \multirow[t]{3}{*}{ Tobacco use } & Current user & 11 & 6 & $4.11(1.48-11.43)$ & $8.99(2.03-39.87)$ & $0.004 *$ \\
\hline & Past user & 6 & 4 & $3.36(0.93-12.18)$ & $3.83(0.63-23.33)$ & 0.145 \\
\hline & Non consumer & 74 & 193 & 1 & 1 & \\
\hline \multirow[t]{3}{*}{ Alcohol consumption } & Current consumer & 30 & 28 & $2.79(1.56-4.99)$ & $1.76(0.75-4.12)$ & 0.194 \\
\hline & Past consumer & 12 & 11 & $2.85(1.20-6.73)$ & $2.05(0.52-8.09)$ & 0.304 \\
\hline & Active & 37 & 101 & 1 & 1 & \\
\hline \multirow[t]{3}{*}{ Physical activity } & Optimal & 48 & 111 & $1.18(0.71-1.96)$ & $1.17(0.52-2.63)$ & 0.703 \\
\hline & Inactive & 31 & 20 & $4.23(2.15-8.32)$ & $3.66(1.21-11.07)$ & $0.022 *$ \\
\hline & Low & 3 & 17 & $0.41(0.12-1.44)$ & $0.88(0.19-4.13)$ & 0.874 \\
\hline \multirow[t]{2}{*}{ Salt consumption } & Optimal & 89 & 208 & 1 & 1 & \\
\hline & High & 24 & 7 & $8.01(3.33-19.28)$ & $5.23(1.48-18.49)$ & $0.010 *$ \\
\hline \multirow{3}{*}{ Stress } & Yes & 52 & 45 & $3.38(2.07-5.51)$ & $5.18(2.42-11.09)$ & $0.000 *$ \\
\hline & No & 64 & 187 & 1 & 1 & \\
\hline & Good knowledge & 3 & 16 & $0.45(0.13-1.64)$ & $0.64(0.09-4.54)$ & 0.651 \\
\hline \multirow[t]{2}{*}{ Knowledge } & Medium knowledge & 39 & 94 & 1 & 1 & \\
\hline & Poor knowledge & 74 & 122 & $1.46(0.91-2.34)$ & $8.82(3.15-24.72)$ & $0.000 *$ \\
\hline \multirow[t]{2}{*}{ Diabetes mellitus } & Yes & 9 & 3 & $6.42(1.70-24.20)$ & $8.42(1.45-48.98)$ & $0.018 *$ \\
\hline & No & 10 & 229 & 1 & 1 & \\
\hline \multirow{2}{*}{ Renal disease } & Yes & 10 & 8 & $2.64(1.01-6.89)$ & $1.98(0.42-9.23)$ & 0.386 \\
\hline & No & 106 & 224 & 1 & 1 & 1 \\
\hline
\end{tabular}

\subsection{Discussions}

The present study assessed determinants of hypertension among adults in Bole Sub-city in Addis Ababa, Ethiopia. The study found that age, average family monthly income, family history of hypertension, tobacco use, physical activities, salt consumption, stress, knowledge, diabetic mellitus status and body mass index were significantly associated with hypertension. The odds of developing hypertension among respondents of age 36-45 years and greater than 45 years old were more than six and seven-times the odds of those participants aged 25-35 years old respectively. This might be due to the fact that as age increases the risk of hypertension might increase and hormonal changes as a result of ageing might cause high blood pressure. This is consistent with studies conducted in Addis Ababa, Durame and Nigeria [9, 14, 18].

The odds of developing hypertension among respondents with average family monthly income of $>10,000.00$ Ethiopian Birr were more than six-times the odds of those respondents with average monthly income of $<5000.00$ Ethiopian Birr. This might be due to difference in economic status. As income increase life style (such as eating style and physical activities) might be changed this might increase the risk of hypertension. This is similar with a study conducted in Jigjiga [19]. The odds of developing hypertension among respondents who had family history of hypertension were more than four-times the odds of those who had no family history of hypertension. This might be due to family members share genes, behaviors, lifestyles, and environments which might increase the risk of hypertension and was consistent with the studies conducted in Western Rajasthan, Malaysia and Jigjiga [19-21].

The odds of developing hypertension among respondents who had over weight were more than three-times the odds of those who had normal weight. This might be due to as BMI increases the number of tissues becomes more and the cell size becomes bigger with increase in the weight that might increase the risk of hypertension. This finding is congruent with the studies conducted in India, Gondar and Bahr Dar [16, 22, 23]. The odds of developing hypertension among respondents who were physically inactive were more than three-times the odds of those who are physically active. This might be due to the fact that exercise (during recreation, traveling, working and regular exercise) has effects in protecting heart disease and diseases of the blood vessels, including high BP. This is similar with studies conducted in Nepal, Malaysia and Kenya [21, 24, 25]. The odds of developing hypertension among respondents who use tobacco currently were more than eight-times the odds of those who had never use tobacco. This might be due to the fact that tobacco use increases the risk of atherosclerosis which leads to increases pressure of the flow of the blood in arteries thus leading to hypertension. This is consistent with the studies conducted in Vietnamese and Gilgel, Ethiopia [26, 27]. 
The odds of developing hypertension among respondents who had high salt consumption were more than five-times the odds of those who had optimal salt consumption. This might be due to the facts that sodium retains fluid inside the body. This increases intravascular volume of fluid in the body leading to high BP. This is similar with reports in Durame and evidence observed and reported in Africa [11, 18]. The odds of developing hypertension among respondents who had stress were more than five-times the odds of those who had no stress. This might be due to the fact that a situation of stress resulted in pronounced increase in the level of BP. This is consistent with studies conducted in Arba Minch and Tigray [28, 29]. The odds of developing hypertension among respondents who had poor knowledge were more than eight-times the odds of those who had medium knowledge. This might be as knowledge increases on hypertension and the risk factors of hypertension the exposure to the risk of hypertension might decreases. This is consistent with studies conducted in Karkala and Tanzania [30, 31].

The odds of developing hypertension among respondents who had diabetes mellitus were more than eight-times the odds of those who had no diabetes mellitus. This might be due to the fact that the presence of diabetic mellitus might increase the risk of hypertension. This is consistent with studies conducted in Bahir Dar and Addis Ababa [16, 32]. It is interesting to note that contrary to a study conducted in Jigjiga [19], the present study showed that about $50.8 \%$ cases and $56.4 \%$ controls were male. However, being male did not significantly associated with hypertension. This is the difference in study population. In addition, marital status, education status, alcohol use and renal disease status were not significantly associated in the current study as compared to studies conducted in Jigjiga, Nigeria, Arba Minch and Addis Ababa [9, 28, 33, 34], This might be due the difference in exposure, study population, study setting and study design.

\section{CONCLUSION}

The current study found that cases had higher exposure to risk factors of hypertension than the controls among adults of the community in Bole Sub-city, Addis Ababa. Age, average family monthly income, family history of hypertension, tobacco use, physical activity, salt consumption, stress, diabetic mellitus status, body mass index and knowledge about hypertension were significantly associated with hypertension. Appropriate preventive and control interventions at all levels might facilitate to minimize exposure to hypertension risk factors which could cause the social, health and economic consequences among the community of the Bole sub-city. Therefore, health educations to promote the life style modifications including cessation of smoking, regular exercise, relieving stress, reducing salt consumption and regular check up for hypertension are important.

\section{ACKNOWLEDGEMENTS}

The authors would like to thank the data collectors for their collaboration during the data collection. We would also like to thank the study participants.

\section{REFERENCES}

[1] Global Burden of Disease. Causes of Death Collaborators, "Global, regional, and national age-sex-specific mortality for 282 causes of death in 195 countries and territories, 1980-2017: a systematic analysis for the global burden of disease study 2017," Lancet, vol. 392, no. 10159, pp. 1736-1788, 2018.

[2] Zhou D, Xi B, Zhao M., "Uncontrolled hypertension increases risk of all-cause and cardiovascular disease mortality in US adults: the NHANES III linked mortality study,"Scientific Reports, vol. 8, pp. 9418-20, 2018.

[3] Danaei G, Finucane M, Lin J., "National, regional, and global trends in systolic blood pressure since 1980: systematic analysis of health examination surveys and epidemiological studies with 786 country-years and $5 \cdot 4$ million participants," The Lancet, vol. 377, no. 9765, pp. 568-577, 2011.

[4] World Health Organization IrfIS, A global brief on hypertension: silent killer, global public health crisis: World Health Day 2013, 2013.

[5] Micael J., "Worldwide prevalence of hypertension exceeds 1.3 billion," Journal of the American Society of Hypertension, vol. 10, no.10, pp. 253-754, 2016.

[6] Incoom S, Martin A, Wisdom T, Wisdom K, Richard O, Phyllis A, et al.,"Prevalence and awareness of hypertension among urban and rural adults in Hohoe Municipality, Ghana," The Journal of Medical Research, vol. 3, no. 3, pp. 136-45, 2017.

[7] Bowry A.D., et al., "The Burden of Cardiovascular Disease in Low- and Middle-Income Countries: Epidemiology and Management," Canadian Journal of Cardiology, vol. 31, no. 9, pp. 1151-1159, 2015.

[8] Anastase D., et al., "Roadmap to Achieve 25\% Hypertension Control in Africa by 2025," Cardiovascular Journal of Africa, vol. 28, no. 4, pp. 262-272, 2014. 
[9] Gudlavalleti V., et al., "Prevalence and risk factors for hypertension and association with ethnicity in Nigeria," Cardiovascular Journal of Africa, vol. 24, pp. 344-350, 2013.

[10] Solomon W, Esayas K, Tigestu A., "Assessment of Blood Pressure Control among Hypertensive Patients in Southwest Ethiopia," Plos one, vol. 11, no. 11, pp. 1-12, 2016.

[11] Steven V, et al., "Status Report on hypertension in Africa: Consultative review for the 6th Session of the African Union Conference of Ministers of Health on NCD's," Pan African Medical Journal, vol. 16, no. 38, 2013.

[12] Felix K, et al., "Predicting physical activity energy expenditure using accelerometry in adults from Sub-Sahara Africa," Obesity, vol. 17, no. 8, pp. 1588-95, 2012.

[13] Kelemu T, Yonatan M., "Prevalence of hypertension in Ethiopia: a systematic meta-analysis," Public Health Reviews, vol. 36, no. 14, pp. 1-12, 2015.

[14] Senbeta G, Yeweyenhareg F, Miftah A., "Prevalence of hypertension and pre-hypertension in Addis Ababa, Ethiopia: A survey done in recognition of World Hypertension Day, 2014," Ethiopian Journal of Health Development, vol. 29, no. 1, pp. 22-30, 2015.

[15] World Population Review, World Population by Country 2017 [cited 2019]. [Online]. Available in: https://worldpopulationreview.com/

[16] Zelalem A., "Prevalence and correlation of hypertension among adult population in Bahir Dar city, northwest Ethiopia: Acommunity based cross-sectionalstudy," International Journal of general Medicine, vol. 8, pp. 175-185, 2015.

[17] World Health Organization, STEPS wise approach to non-communicable diseases and their risk factors surveillance (STEPS), 2019. [Online]. Available in: https://www.who.int/ncds/surveillance/steps/riskfactor/en/

[18] Tsegab P., Yalemzewod A., Akilew A., "Prevalence and Associated Factors of Hypertension among Adults inDurame Town, Southern Ethiopia," Plos One, vol. 9, no. 11, pp. 1-9, 2014.

[19] Henok A., Frew T., Ermias B., "Prevalence and associated factors of hypertension among adults in Ethiopia: A community based cross-sectional study," BMC Research Notes, vol. 10, no. 1, pp. 629, 2017.

[20] Priya J., et al., "Co-Relation of Family History of Hypertension with Hypertension in the Young Male Adults in Western Rajasthan," Indian Journal of Clinical Anatomy and Physiology, vol. 2, no. 4, pp. 223-225, 2015.

[21] Loh K., "The Association Between Risk Factors and Hypertension in Perak, Malaysia," Medical Journal of Malasyia, vol. 68, no. 4, pp. 291-296, 2013.

[22] Sushil K., et al., "The prevalence of hypertension and hypertension risk factors in a rural Indian community: A prospective door-to-door study," Journal of Cardiovascular Disease Research, vol. 3, no. 2, pp. 117-23, 2010.

[23] Solomon M., et al., "Prevalence and Associated Factors of Hypertension, A cross-sectional community based study in Northwest Ethiopia," Plos One, vol. 10, no. 4, pp. 1-11, 2015.

[24] Beatrice O., et al., "Risk factors of hypertension among adults aged 35-64 years living in an urban slum Nairobi, Kenya," BMC Public Health, vol. 15, no. 1251, pp. 1-9, 2015.

[25] R. R, Achyut R., et al., "Prevalence and Associated Factors of Hypertension in Municipalities of Kathmandu, Nepal," International Journal of Hypertension, pp.1-10, 2016.

[26] Fessahaye A., et al., "Risk factors for hypertension among adult. An analysis of survey data on chronic non-communicable disease at Gilgel gibe field research center, south west Ethiopia; Population based study," Ethiopian Journal of Health Science, vol. 3 no. 2, pp. 281-290, 2015.

[27] Thuy A., "The association between smoking and hypertension in a population-based sample of Vietnamese men," Journal of Hypertension, vol. 28, no. 2, 2010.

[28] Aschenaki K., et al., "Prevalence and Associated Factors of Hypertension among Civil Servants Working in Arba Minch Town, South Ethiopia," International Journal of Public Health Science, vol. 5, no. 4, pp. 375-383, 2016.

[29] Alemayehu B., Susan B., Eva K., "Determinants of hypertension among adults in Tigray, Northern Ethiopia: A Matched case-control study," International Journal of Non-communicable Disease, vol. 2, no. 2, pp. 36-44, 2017.

[30] Yathi Kumara S, Ashok N., "A Study to Assess the Knowledge and Practices Regarding Life Style Modification among Hypertensive Patients in the Selected Hospitals of Karkala and Mangalore Taluk," Journal of Biology, Agriculture and Healthcare, vol. 3, no.16, pp. 48-53, 2013.

[31] John M., et al., "Hypertension control and its correlates among adults attending a hypertension clinic in Tanzania," Journal of Clinical Hypertension, vol. 18, no. 3, pp. 207-16, 2016.

[32] Tariku T., "Assessment of the Prevalence of Hypertension and Associated Factors Among Ethiopian Federal Police Officers Addis Ababa, Ethiopia: A Community Based Cross-Sectional Study,” EC Cardiology, vol. 2, no. 6, pp. 278-286, 2017.

[33] Wubareg S., et al., "Behavioral Risk Factors of Hypertension among Pastoral and Agro Pastoral Adult Communities, Eastern Ethiopia, Somali Regional State,” Journal of Tropical Diseases, vol. 5, no. 2, pp. 2-6, 2016.

[34] Kore C., Yohannes H., "Prevalence of Chronic Kidney Disease and Associated factors among Patients with Kidney Problems Public Hospitals in Addis Ababa, Ethiopia,” Journal of Kidney, vol. 4, no. 1, pp.2-5, 2018.

Int. J. Public Health Sci, Vol. 9, No. 2, June 2020: 121 - 128 